\title{
Different natural rubber latex sensitisation and allergy in patients with spina bifida, urogenital disorders and oesophageal atresia compared with a normal paediatric population and atopic children Reinhold Cremer*, Marcus Lorbacher, Fritz Hering and Reinold Engelskirchen
}

Address: Children's Hospital of the City of Cologne, Amsterdamer Str. 59, 50735 Cologne, Germany

Email: Reinhold Cremer* - reinhold.cremer@t-online.de

* Corresponding author

\author{
from 50th Annual Meeting of the Society for Research into Hydrocephalus and Spina Bifida \\ Cambridge, UK. 30 August - 2 September 2006 \\ Published: 21 December 2006 \\ Cerebrospinal Fluid Research 2006, 3(SuppI I):S24 doi:I0.I 186/I743-8454-3-SI-S24
}

(c) 2006 Cremer et al; licensee BioMed Central Ltd.

\section{Background}

Natural rubber latex (NRL) contains proteins, which after repeated contacts with latex products and an allergic predisposition (atopy) can lead to a sensitization (specific IgE against NRL proteins) or allergy (type 1 allergy with symptoms from urticaria to allergic shock). From previous investigations spina bifida patients are known to be a high risk group for latex allergy and sensitization due to numerous operations beginning soon after birth. In the study presented we compared spina bifida patients with patients who also underwent operations repeatedly beginning soon after birth (urologic malformations) or with one surgery in the neonatal period and numerous anaesthesias due to repeated treatment with a bougie (oesophageal atresia).

\section{Materials and methods}

We investigated the prevalence of NRL-specific IgE $(>0.35$ $\mathrm{kU} / \mathrm{l}$, ImmunoCAP systeme) in a normal pediatric population (neither atopy nor surgeries) [group I], atopic chil- dren [group II], spina bifida patients [group III], children with urogenital malformations [group IV] and oesophago-tracheal malformations [group V].

\section{Results}

Apart from atopy the number of operations could be identified as risk factor for developing NRL-sensitization and allergy (group III, IV). The prevalence of latex allergy seems to be lower after repeated anaesthesia (group V) than after repeated surgery. See Table 1.

\section{Conclusion}

Besides the known high-risk group of spina bifida patients also other patients with congenital malformations and early surgery present with a remarkable risk for latex sensitization. For patients with malformations where repeated surgery can be expected, prophylactic measures similar to those for spina bifida patients should be established.

Table I:

\begin{tabular}{llllll}
\hline Group & I & II & III & IV & V \\
\hline Number of patients & 54 & 44 & 183 & 53 & 17 \\
\% NRL-sensitized & 4 & 14 & 48 & 17 \\
$\%$ NRL-allergic & 0 & 0 & 18 & 8 & 0 \\
\hline
\end{tabular}




\section{Cerebrospinal Fluid Research}

Open Access

Page 2 of 2 